\title{
Cerebral Imaging in Patients with COVID-19 and Neurological Symptoms: First Experience from two University Hospitals in Northern Germany
}

\author{
Zerebrale Bildgebung bei Patienten mit COVID-19 \\ und neurologischer Symptomatik: Erste Erfahrung \\ aus 2 norddeutschen Universitätskrankenhäusern
}

Authors

Ulf Jensen-Kondering ${ }^{1}$, Alexander Neumann², Nils G. Margraf ${ }^{3}$, Felix Gövert ${ }^{3}$, Norbert Brüggemann ${ }^{4}$, Domagoj Schunk ${ }^{5}$, Thomas Bahmer ${ }^{6}$, Peter Schramm², Stefan Schreiber ${ }^{6}$, Olav Jansen ${ }^{1}$

Affiliations

1 Department of Radiology and Neuroradiology, University Hospital Schleswig-Holstein, Campus Kiel, Germany

2 Institute of Neuroradiology, University Hospital SchleswigHolstein, Campus Lübeck, Germany

3 Department of Neurology, University Hospital SchleswigHolstein, Campus Kiel, Germany

4 Department of Neurology, University Hospital SchleswigHolstein, Campus Lübeck, Germany

5 Emergency Department, University Hospital SchleswigHolstein, Campus Kiel, Germany

6 Department of Internal Medicine I, University Hospital Schleswig-Holstein, Campus Kiel, Germany

Key words

brain, CNS, CT, infection, MR imaging

received 18.07.2020

accepted 04.09.2020

published online 19.11.2020

Bibliography

Fortschr Röntgenstr 2021; 193: 667-671

DOI 10.1055/a-1265-7209

ISSN 1438-9029

(c) 2020. Thieme. All rights reserved.

Georg Thieme Verlag KG, Rüdigerstraße 14,

70469 Stuttgart, Germany

Correspondence

Herr Dr. Ulf Jensen-Kondering

Department of Radiology and Neuroradiology, University

Hospital Schleswig-Holstein, Campus Kiel,

Arnold-Heller-Str. 3, Haus 41, 24116 Kiel, Germany

Tel.: $+49 / 431 / 5974806$

Fax: $+49 / 431 / 5974913$

Ulf.Jensen-Kondering@uksh.de

\section{ABSTRACT}

Purpose To describe findings on cerebral imaging in patients with COVID-19 and neurological symptoms at two German university hospitals.

Materials and Methods Patients with COVID-19 and neurological symptoms and cerebral imaging (CT or MRI) were included. A chart review regarding neurological symptoms, COVID-19 and imaging findings was conducted.

Results 12 patients ( 4 females, age $68 \pm 12$ years) could be included. Three patients had acute findings. Two patients had acute and subacute cerebral ischemia, one patient had additional intracranial hemorrhages and presumed central pontine myelinolysis. One patient had presumed COVID-19associated pansinusitis.

Conclusion Findings on cerebral imaging in patients with COVID-19 are uncommon and nonspecific. However, cerebral ischemia is regularly encountered and patients should be evaluated for stroke symptoms.

Key Points:

- Approx. 20 \% of patients with COVID-19 develop neurological symptoms.

- Findings on cerebral imaging in patients with COVID-19 are heterogeneous and nonspecific.

- The most common findings are cerebral ischemia and hemorrhages.

\section{Citation Format}

- Jensen-Kondering U, Neumann A, Margraf N et al. Cerebral Imaging in Patients with COVID-19 and Neurological Symptoms: First Experience from two University Hospitals in Northern Germany. Fortschr Röntgenstr 2021; 193: 667671

\section{ZUSAMMENFASSUNG}

Ziel Beschreibung von klinischen und radiologischen Befunden von Patienten mit COVID-19 und neurologischen Symptomen an 2 deutschen Universitätskrankenhäusern. 
Material und Methoden Einschluss aller Patienten mit COVID-19 und zerebralen neurologischen Symptomen. Retrospektive Durchsicht der Krankenunterlagen hinsichtlich der neurologischen Symptome und COVID-19 sowie der Befunde der zerebralen Bildgebung (CT und MRT).

Ergebnisse 12 Patienten (4 Frauen, Alter $68 \pm 12$ Jahre) konnten eingeschlossen werden. Drei Patienten zeigten akute Befunde. Zwei der Patienten hatten akute und subakute zerebrale Ischämien, 1 Patient hatte zusätzliche intrakranielle
Blutungen und mutmaßlich eine zentrale pontine Myelinolyse. Ein Patient hatte eine mutmaßlich COVID-19-assoziierte Pansinusitis.

Schlussfolgerung Auffälligkeiten in der zerebralen Bildgebung bei Patienten mit COVID-19 und neurologischen Symptomen sind eher selten und unspezifisch. Allerdings sind zerebrale Ischämien bei Patienten mit COVID-19 anzutreffen und es sollte ein besonderes Augenmerk auf Symptome von zerebralen Ischämien gelegt werden.

\section{Introduction}

In December 2019, the first cases of pneumonia caused by a novel coronavirus (SARS-CoV2) were identified in Wuhan/China. The virus has since spread around the globe. The disease caused by SARS-CoV2, known as COVID-19, is typically characterized by a respiratory infection with cough and fever. However, other organ systems can also be infected at an early stage in some cases [1, 2]. According to an initial large retrospective analysis from Wuhan, approximately one third (36.4\%) of COVID-19 patients exhibit neurological manifestations [3]. The neuroinvasive potential of coronaviruses is already known. Neurological symptoms were able to be observed in SARS-CoV1 and MERS-CoV patients $[4,5]$. At the end of June 2020, 193243 cases in Germany and 3146 (108.6 per 100000 inhabitants were reported in SchleswigHolstein) (https://www.rki.de/DE/Content/InfAZ/N/Neuartiges_ Coronavirus/Fallzahlen.html, as of 6/27/2020). In total, 68 patients had been hospitalized at both sites of the University Hospital of Schleswig-Holstein. We report on our first experience with cerebral imaging in COVID-19 patients with neurological symptoms.

\section{Materials and Methods}

All patients infected with SARS-CoV2 who underwent clinically indicated cerebral imaging were retrospectively included. Imaging findings were evaluated with respect to primary and secondary findings. The following were categorized as primary findings: acute pathologies that were the presumably cause of symptoms or presumably occurred during the infection or as a result of the infection. All pathological findings classified as preexisting were considered secondary findings. In addition, demographic data and clinical information regarding SARS-CoV2 infection were recorded.

\section{Results}

12 patients ( 4 women, 8 men, average age $68+12$ years) were able to be included ( $\vee$ Table 1a). Two of the patients were examined after the infection had resolved. Three COVID-19 cases were mild, five were moderate, and four were severe (mild: no hospitalization, hospitalization without oxygen supply, moderate: oxygen supply, severe: intensive care). MRI examination was performed in two patients, CT examination in seven patients (including additional CT angiography in one case), and three additional patients underwent both CT and MRI. All MRI examinations were performed with IV contrast agent.

In one severe case of COVID-19, a brain stem lesion was detected and classified as presumed central pontine myelinolysis ( Fig. 1). Two patients had acute and subacute cerebral ischemia ( $\triangleright$ Fig. 2). One patient additionally had a combination of subarachnoid and parenchymal hemorrhages ( $>$ Fig. 3 ). One patient had presumed COVID-19-associated sinusitis based on headache, imaging finding, and a positive PCR for SARS-CoV2 from a nasal swab ( $\triangleright$ Fig.4). None of the patients had acute inflammatory intracranial changes. No acute findings could be identified on imaging in the remaining patients. The most common secondary findings were preexisting microangiopathic white matter damage $(n=4)$ and old embolic and microangiopathic stroke $(n=2)$. The neurological symptoms occurred with the start of the other symptoms in six patients, over the course of hospitalization in four cases, and weeks later in two patients. Eight patients experienced complete resolution of their neurological symptoms, one patient was discharged in soporose state, and three patients died ( $\vee$ Table $1 \mathbf{b})$.

\section{Discussion}

Initial imaging results in a series of 58 patients with severe cases of COVID-19 were published by Helms et al. [6]. Meningeal contrast enhancement was seen in 8 of 13 patients (62\%) and cerebral ischemia in 3 patients ( $23 \%$ ).

Kandemili et al. report on patients with severe cases of COVID-19 in Turkey [7]. Cortical signal changes in FLAIR weighting accompanied by cortical diffusion impairment, leptomeningeal enhancement, or cortical blooming artifacts were seen in $10 / 27$ patients (37\%).

Radmanesh report on 242 patients (of a total of 3661 patients, $6.6 \%$ with neurological symptoms in New York, who were examined primarily with CT. 13 patients (4.5\%) had acute or subacute ischemic infarct and 11 patients (3.8\%) intracranial hemorrhages. The majority of patients had no specific changes, particularly no meningeal contrast enhancement [8].

The high prevalence of cases of cerebral ischemia occurring in association with COVID-19 is noteworthy. Case series from France [9], the USA [10], and Italy [11] show a significantly worse clinical neurological outcome and a greater mortality rate in patients with COVID-19 and cerebral ischemia compared to patients without 
- Table 1a Clinical and radiological information regarding the included patients in chronological order. Sex and age are not individually specified.

\begin{tabular}{|c|c|c|c|c|c|c|}
\hline$\#$ & site & $\begin{array}{l}\text { severity of } \\
\text { COVID-19 }\end{array}$ & $\begin{array}{l}\text { neurological } \\
\text { symptoms, } \\
\text { reason for imaging }\end{array}$ & modality & primary findings & secondary findings \\
\hline 1 & Kiel & moderate & confusion & $\mathrm{CT}$ & - & $\begin{array}{l}\text { pronounced microangiopathic } \\
\text { white matter damage, Old } \\
\text { embolic infarcts }\end{array}$ \\
\hline 2 & Kiel & moderate & confusion, fall & $\mathrm{CT}$ & - & $\begin{array}{l}\text { minimal microangiopathic } \\
\text { white matter damage }\end{array}$ \\
\hline 3 & Kiel & mild & $\begin{array}{l}\text { temporary loss of } \\
\text { consciousness }\end{array}$ & CT & - & $\begin{array}{l}\text { pronounced microangiopathic } \\
\text { white matter damage, Old } \\
\text { embolic infarcts }\end{array}$ \\
\hline 4 & Lübeck & severe & $\begin{array}{l}\text { Impaired } \\
\text { consciousness }\end{array}$ & CT, CTA & - & residuals after AVM surgery \\
\hline 5 & Kiel & moderate & confusion, fall & $\mathrm{CT}$ & - & $\begin{array}{l}\text { minimal microangiopathic } \\
\text { white matter damage }\end{array}$ \\
\hline 6 & Kiel & mild & right paresthesia & MRI, CT & subacute embolic infarcts & $\begin{array}{l}\text { arteriosclerosis of the intracranial } \\
\text { vessels }\end{array}$ \\
\hline 7 & Kiel & severe & $\begin{array}{l}\text { Impaired } \\
\text { consciousness }\end{array}$ & $\mathrm{CT}, \mathrm{MRI}$ & $\begin{array}{l}\text { subacute and acute infarcts, } \\
\text { diffuse subarachnoid hemor- } \\
\text { rhage, cerebellar intracereb- } \\
\text { ral hemorrhage, primarily } \\
\text { central pontine myelinolysis }\end{array}$ & - \\
\hline 8 & Kiel & moderate & headache & MRI & pansinusitis & - \\
\hline 9 & Lübeck & severe & $\begin{array}{l}\text { Impaired } \\
\text { consciousness }\end{array}$ & $\mathrm{CT}$ & - & - \\
\hline 10 & Lübeck & mild & $\begin{array}{l}\text { dizziness, sudden } \\
\text { hearing loss }\end{array}$ & $\mathrm{CT}, \mathrm{MRI}$ & - & - \\
\hline 11 & Lübeck & severe & $\begin{array}{l}\text { Impaired } \\
\text { consciousness }\end{array}$ & $\mathrm{CT}$ & - & - \\
\hline 12 & Kiel & moderate & $\begin{array}{l}\text { hyposmia and } \\
\text { hypogeusia }\end{array}$ & MRI & - & - \\
\hline
\end{tabular}

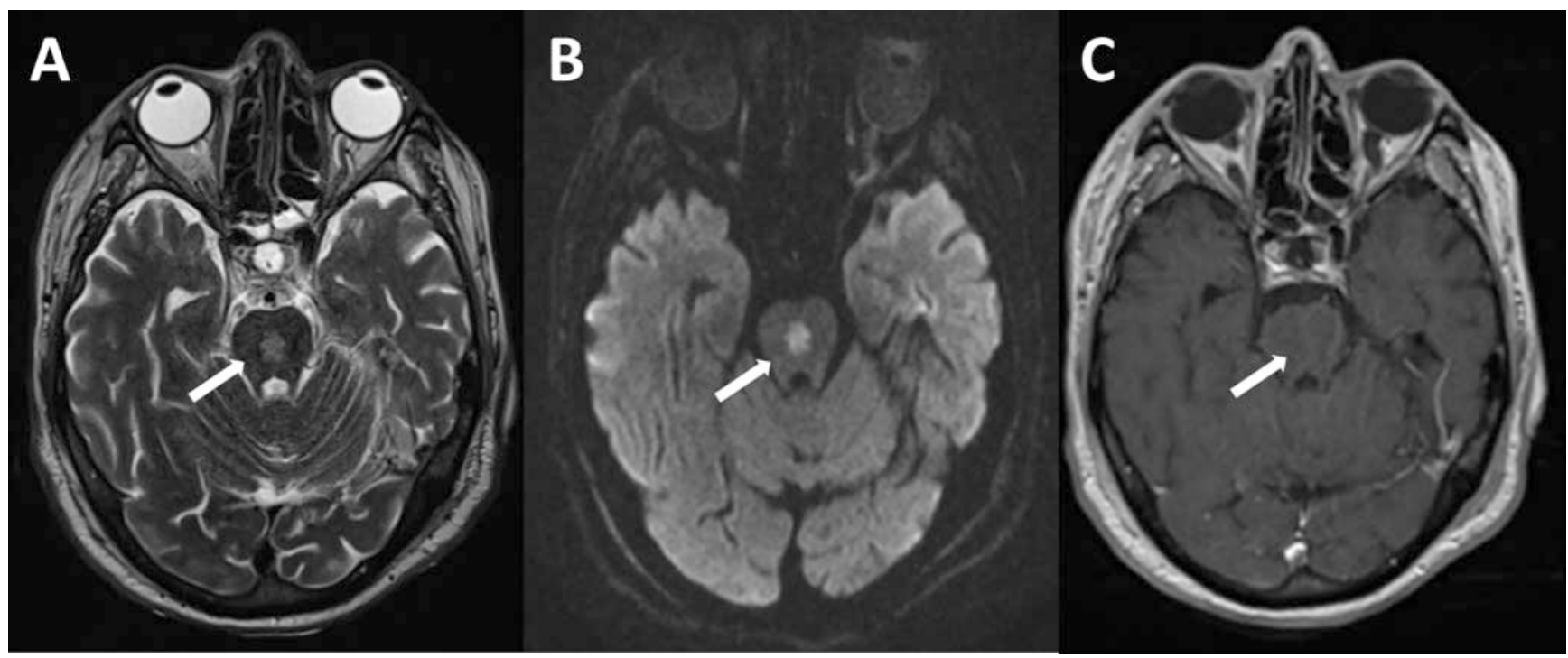

- Fig. 1 Presumed central pontine myelinolysis in a patient with severe and prolonged COVID-19 course. Hyperintense central pontine lesion in T2w images. A with corresponding diffusion impairment $\mathbf{B}$ but without contrast enhancement $\mathbf{C}$ after contrast agent administration. While hospitalized, the patient showed no hyponatremia and no relevant hypernatremia but now requires dialysis. There were no laboratory findings prior to the patient being transferred to us. Lumbar puncture was not performed. 


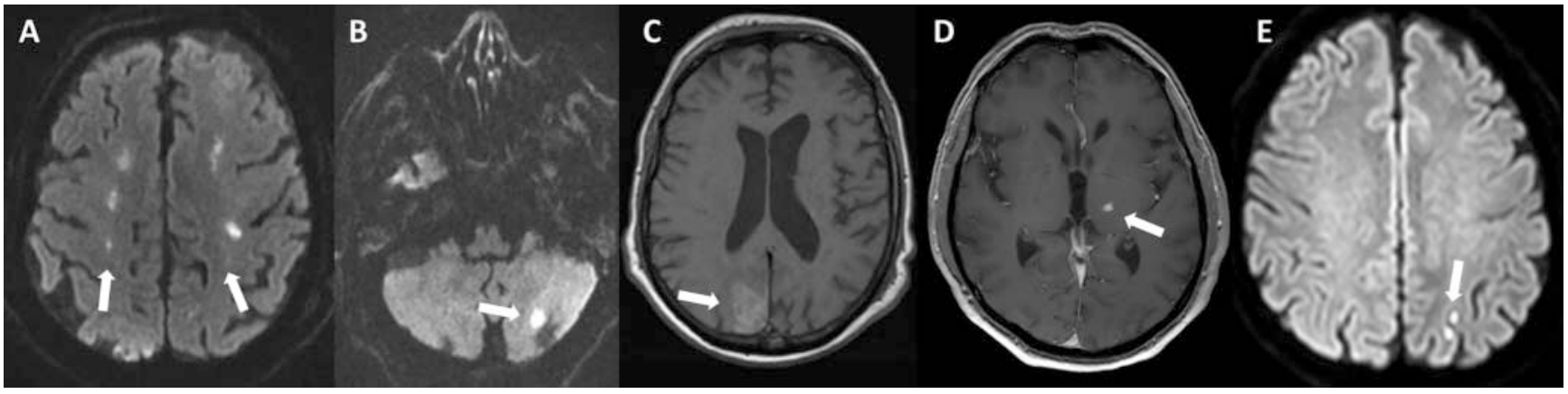

- Fig. 2 Cerebral ischemia pattern. Bilateral hemodynamic stroke along the inner boundary zone $\mathbf{A}$. Acute left cerebellar infarction in the territory of the inferior posterior cerebellar artery B. Subacute hemorrhagic infarction in the territory of the right posterior cerebral artery $\mathbf{C}$. Subacute infarction of the left thalamus with contrast enhancement $\mathbf{D}$ and also small left parietal infarcts.

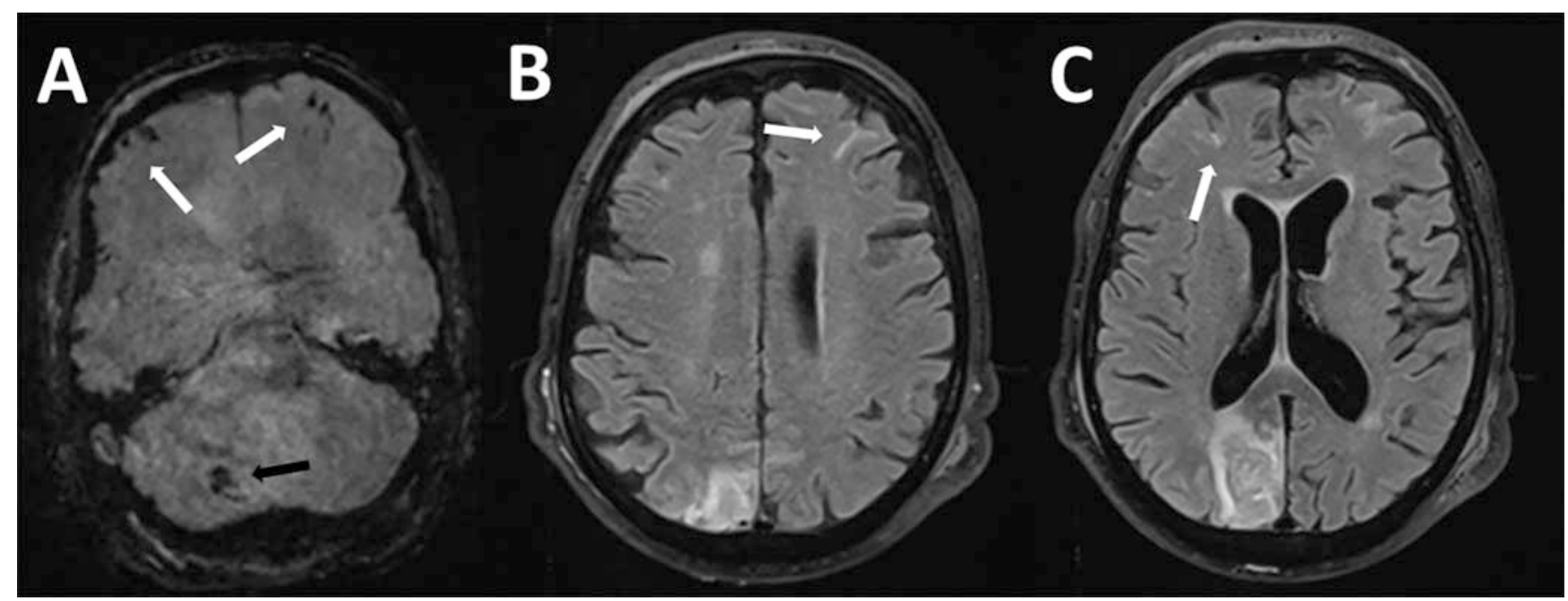

- Fig. 3 Right cerebellar parenchymal hemorrhage (dark arrow) and bifrontal subarachnoid hemorrhages (light arrows) in a susceptibility-weighted sequence and additional axial FLAIR B, C to show the extraaxial localisation of the bifrontal hemorrhages (light arrows). Prior to acquisition of the MRI scan, anticoagulation therapy was performed to treat a pulmonary artery embolism with low-molecular heparin (tinzaparin) administered subcutaneously followed by unfractionated heparin with a target PTT of 70-80 s and then rivaroxaban and clopidogrel.

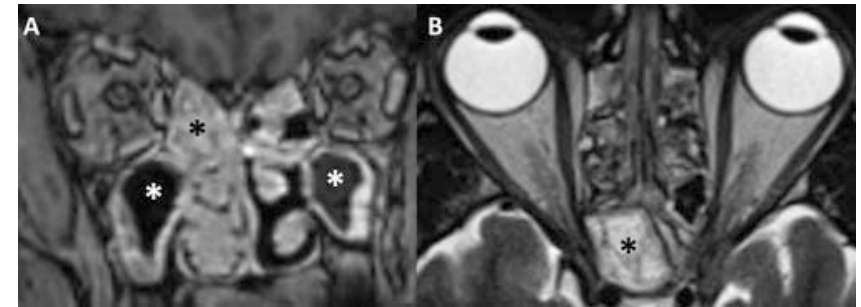

- Fig. 4 Presumed COVID-19-associated pansinusitis with bilateral involvement of the maxillary sinus (white stars), the ethmoidal cells (black star, A) in contrast-enhanced T1w images, and of the sphenoid sinus (B, black star) in T2w images.

COVID-19 and cerebral ischemia. In addition, COVID-19 was identified as an independent risk factor for cerebral ischemia [12].

As in other collectives, the frequency of neurological symptoms (approx. 18\%) in our cohort is lower than that reported by Mao et al. One reason for this is that we only included patients with neurological symptoms resulting in cerebral imaging. Two patients in our cohort had cerebral ischemia (approx. 17\%) and one patient (approx. $8 \%$ ) had intracranial hemorrhages. However, most patients did not have any acute pathologies which corresponds with the literature.

Various damage mechanisms of the CNS have been discussed. 1) Direct neuroinvasion by SARS-CoV; 2) Secondary cerebral damage caused by ischemia and bleeding due to possible endothelial dysfunction and systemic hypercoagulability and possibly due to thromboses of the small cerebral veins caused by cerebral hemorrhages [13]. 3) Indirect damage due to cytokines and post-infection antibodies [14]. To date, it has not been possible to clearly define the damage pattern and the clarify which mechanisms are most prevalent and how frequently they occur. Neuropathological correlation studies are necessary to answer these questions and to identify a causality between the infection and damage patterns [15].

We present the first German case series from a minimally affected region. Our study includes COVID-19 patients with mild, moderate, and severe disease courses who underwent neurora- 
- Table 1b Time of occurrence and outcome regarding neurological symptoms.

\begin{tabular}{|l|l|l|l|}
\hline$\#$ & neurological symptoms & start of neurological symptoms & outcome \\
\hline 1 & confusion & with other symptoms & death \\
\hline 2 & confusion & with other symptoms & asymptomatic \\
\hline 3 & temporary loss of consciousness & with other symptoms & asymptomatic \\
\hline 4 & Impaired consciousness & during hospitalization & asymptomatic \\
\hline 5 & confusion & with other symptoms & asymptomatic \\
\hline $\mathbf{6}$ & right paresthesia & weeks later & asymptomatic \\
\hline $\mathbf{7}$ & Impaired consciousness & during hospitalization & soporose \\
\hline 10 & headache & with other symptoms & asymptomatic \\
\hline 11 & Impaired consciousness & during hospitalization & death \\
\hline 12 & dizziness, sudden hearing loss & weeks later & asymptomatic \\
\hline & Impaired consciousness & during hospitalization & death \\
\hline
\end{tabular}

diological imaging and includes post-infection data and data regarding newly occurring neurological symptoms. In summary, these findings are currently still heterogeneous and nonspecific. Further long-term studies are needed to detect potential residual and late effects of COVID-19. In this regard, we initiated a population-based cohort study www.covidom.de.

\section{Conflict of Interest}

The authors declare that they have no conflict of interest.

\section{References}

[1] Guan W, Ni Z, Hu Y et al. Clinical characteristics of coronavirus disease 2019 in China. New England Journal of Medicine 2020; 382: 1708-1720

[2] Puelles VG, Lütgehetmann M, Lindenmeyer MT et al. Multiorgan and Renal Tropism of SARS-CoV-2. N Engl J Med 2020. doi:10.1056/ NEJMc2011400

[3] Mao L, Jin H, Wang M et al. Neurologic Manifestations of Hospitalized Patients With Coronavirus Disease 2019 in Wuhan, China. JAMA Neurol 2020; 77 (6): 683-690

[4] Tsai LK, Hsieh ST, Chang YC. Neurological manifestations in severe acute respiratory syndrome. Acta Neurol Taiwan 2005; 14: 113-119

[5] Kim JE, Heo JH, Kim HO et al. Neurological Complications during Treatment of Middle East Respiratory Syndrome. J Clin Neurol 2017; 13: 227-233

[6] Helms ], Kremer S, Merdji $\mathrm{H}$ et al. Neurologic Features in Severe SARSCoV-2 Infection. N Engl J Med 2020; 382 (23): 2268-2270
[7] Kandemirli SG, Dogan L, Sarikaya ZT et al. Brain MRI Findings in Patients in the Intensive Care Unit with COVID-19 Infection. Radiology 2020; 297: 201697

[8] Radmanesh A, Raz E, Zan E et al. Brain Imaging Use and Findings in COVID-19: A Single Academic Center Experience in the Epicenter of Disease in the United States. AJNR Am J Neuroradiol 2020. doi:10.3174/ ajnr.A6610

[9] Escalard S, Maïer B, Redjem H et al. Treatment of Acute Ischemic Stroke due to Large Vessel Occlusion With COVID-19: Experience From Paris. Stroke 2020. doi:STROKEAHA120030574

[10] Yaghi S, Ishida K, Torres J et al. SARS-CoV-2 and Stroke in a New York Healthcare System. Stroke 2020; 51 (7): 2002-2011

[11] Benussi A, Pilotto A, Premi E et al. Clinical characteristics and outcomes of inpatients with neurologic disease and COVID-19 in Brescia, Lombardy, Italy. Neurology 2020. doi:10.1212/WNL.0000000000009848

[12] Belani P, Schefflein J, Kihira S et al. COVID-19 Is an Independent Risk Factor for Acute Ischemic Stroke. AJNR Am J Neuroradiol 2020. doi:10.3174/ajnr.A6650

[13] Wu Y, Xu X, Chen Z et al. Nervous system involvement after infection with COVID-19 and other coronaviruses. Brain Behav Immun 2020 doi:S0889-1591(20)30357-3

[14] Nicholson P, Alshafai L, Krings T. Neuroimaging Findings in Patients with COVID-19. AJNR Am J Neuroradiol 2020. doi:10.3174/ajnr.A6630

[15] Solomon IH, Normandin E, Bhattacharyya S et al. Neuropathological Features of COVID-19. N Engl J Med 2020. doi:NEJMc2019373 